Estudos RBEP

\title{
As contribuições da pesquisa-ação para a elaboração de políticas de formação continuada na perspectiva da inclusão escolar
}

\author{
Mariangela Lima de Almeida ${ }^{\mathrm{I}, \text { II }}$ \\ Maria José Carvalho Bento ${ }^{\text {III, IV }}$ \\ Nazareth Vidal da Silva ${ }^{\mathrm{V}, \mathrm{vI}}$
}

http://dx.doi.org/10.24109/2176-6681.rbep.99i252.3466

Universidade Federal do Espírito Santo (UFES). Vitória, Espírito Santo, Brasil. E-mail: mlalmeida.ufes@gmail.com; $<$ http://orcid.org/0000-00 02-7092-2583>.

II Doutora em Educação pela Universidade Federal do Espirito Santo (UFES).Vitória, Espírito Santo, Brasil.

III Universidade Federal do Espírito Santo (UFES). Vitória, Espírito Santo, Brasil. E-mail: <zezebento56@gmail.com>; $<$ http://orcid.org/0000-00 01-5877-2925>.

IV Mestranda em Educação na Universidade Federal do Espírito Santo (UFES).Vitória, Espírito Santo, Brasil.

v Universidade Federal do Espírito Santo (UFES). Vitória Espírito Santo, Brasil. E-mail: <newpedagoga@gmail. com>; <http://orcid.org/000 0-0002-8499-5089>.

vı Mestranda em Educação na Universidade Federal do Espírito Santo (UFES). Vitória, Espírito Santo, Brasil.

\section{Resumo}

Este artigo objetiva analisar o movimento do grupo de gestores de educação especial da Região Serrana/ES, tanto no que se refere à perspectiva do diálogo coletivo, das indagações reflexivas e da corresponsabilização de todos os envolvidos como na proposta e na elaboração de um projeto comum à superintendência regional e aos municípios. Utiliza, como referencial teórico-metodológico, a pesquisa-ação colaborativo-crítica, sustentada pelos pressupostos da teoria do agir comunicativo. O estudo desdobrou-se em três momentos: no primeiro, empregou-se a estratégia dos grupos focais; no segundo, foi criado o grupo de estudo-reflexão; e, no terceiro, acompanhou-se a materialização da construção da proposta de uma política pública de formação continuada. A análise dos dados evidencia que os gestores públicos de educação especial atuam diretamente nos contextos 
da produção do texto e da colocação em prática das políticas públicas de formação continuada, bem como procuram construir, pela via da pesquisaação, outros modos de conceber políticas públicas educacionais, por meio da racionalidade comunicativa. No movimento do grupo, estão presentes sua intencionalidade e sua vontade de construção de uma política pública de formação continuada. A intenção, pressuposto fundante da teoria do agir comunicativo, constitui-se na identidade desse grupo de gestores.

Palavras-chave: formação continuada; gestão em educação especial; pesquisa-ação colaborativo-crítica.

\section{Abstract \\ The contributions of action-research to the development of continuing- education policies from the school inclusion perspective}

This paper analyzes the movement of a group of special-education managers from the Espírito Santo's mountain region, either as regards the perspective of the collective dialogue, the reflections and the accountability of those involved in the process, or as regards the proposal and development of a project pertaining both to the Regional Superintendency and the municipalities. It takes the critical and collaborative action-research as a theoretical and methodological benchmark, supported by postulates of the theory of communicative action. The study unfolded in three parts: in the first, it was employed a focus-group strategy; in the second, a studyreflection group was created; and, in the third, the conception of a proposal for a continuing-education public policy was monitored. Data analysis shows that special-education managers act directly on the context of the writing and employment of continuing-education public policies, as they aim to develop, via action-research, other policy-making processes for education, through communicative rationality. Within the group's movement, their intention and willingness to develop a continuing-education public policy is clear. Such intention, that is a key element of the theory of communicative action, presents itself as the identity of this group of managers.

Keywords: continuing education; management in special education; critical and collaborative action-research. 


\section{Introdução}

Este artigo se propõe a discutir os desafios e as possibilidades de pensar e fazer outros/novos processos formativos, pela via do diálogo e da colaboração, no processo de construção de conhecimentos entre gestores da educação especial dos sistemas de ensino, profissionais e alunos da universidade em contextos capixabas.

De modo particular, busca-se compreender e analisar o movimento do grupo de gestores da educação especial da Região Serrana/ES, tanto no que se refere à perspectiva do diálogo coletivo, das indagações reflexivas e da corresponsabilização de todos os envolvidos como também na proposta e elaboração de um projeto comum à superintendência regional e aos municípios.

O texto está organizado em quatro seções: na primeira, analisam-se as contribuições dos referenciais teórico-metodológicos da pesquisa-ação colaborativo-crítica e contextualiza-se o objeto da pesquisa; na segunda, aborda-se a política pública vigente e sua incidência na pesquisa; na terceira, discutem-se o contex to da elaboração da proposta e o discurso dos gestores de educação especial; por fim, apresentam-se pontos importantes de todo o processo.

\section{A pesquisa-ação colaborativo-crítica e suas contribuições para a formação continuada dos profissionais da educação}

Nos últimos anos, um dos grandes desafios postos à área de educação especial diz respeito à formação contínua dos profissionais, principalmente diante das diretrizes e das propostas para a inclusão escolar. Em diversos estados e municípios brasileiros, essa formação tem ficado sob a responsabilidade de instituições que promovem cursos de aperfeiçoamento e/ou de pós-graduação em nível de especialização, em sua maioria, na modalidade semipresencial e a distância. Há também propostas de formação continuada, promovidas pelas secretarias de educação municipais e estaduais, para atender aos profissionais da educação que atuam nas redes de ensino.

No Brasil, os diversos processos de pesquisa sobre a formação continuada de docentes da educação básica são oriundos de desafios impostos por processos inclusivos nos espaços escolares regulares. Também se originam das políticas públicas propostas em âmbito federal, que representam significativo estímulo para atender a questões particulares em regiões específicas de um território tão amplo como o brasileiro.

Para Almeida (2010), (re)significar a formação continuada é procurar compreender como ocorre essa formação tendo em vista a política educacional direcionada à educação especial na perspectiva inclusiva. A relevância do debate se justifica diante dos argumentos de docentes e técnicos das redes de ensino, que alegam não terem conhecimento acerca dessa área, uma vez que o tema não foi abordado em sua formação inicial. 
Sabe-se que, ainda nos dias atuais, "os modelos mais difundidos de formação de professores são aqueles relacionados ao modelo da racionalidade técnica" (Pereira, 2002, p. 19), submetendo os profissionais a normativas e regras, o que coíbe, consequentemente, modos de produzir conhecimentos sobre eles próprios e sobre as escolas.

Nesse sentido, a perspectiva da pesquisa-ação, em sua acepção crítica, aponta caminhos que colocam os participantes em situações sociais propícias para uma forma de indagação autorreflexiva, a fim de que compreendam os próprios contextos de referência socioeducativos e transformem suas práticas. Assim, sustenta-se, a exemplo de outros autores/pesquisadores, como Franco (2005a, 2005b), Jesus (2007, 2008), Zeichner (1998), Barbier (2002), Carr e Kemmis (1988), a relevância de metodologias investigativas e formativas que permitam "[...] diálogo fecundo, crítico e reflexivo que se estabelece entre intencionalidade e ação" (Franco, 2015, p. 613).

Dessa forma, adota-se a pesquisa-ação em uma perspectiva colaborativo-crítica, como opção teórico-metodológica, que, conforme Carr e Kemmis (1988), consiste em investigação emancipatória, que vincula teorização educacional e prática à crítica, em um processo que se ocupa simultaneamente da ação e da investigação. Portanto, trata-se de uma pesquisa que se sustenta na dialética entre sujeito e objeto, fatos e valores, pensamento e ação, pesquisador e pesquisado, pesquisa e ação. Essa dialética está sustentada nos fundamentos da racionalidade comunicativa, de Jürgen Habermas (1987, 2004).

Acredita-se, assim, na possibilidade de fomentar a construção de práticas educacionais mais inclusivas, mediante a produção de conhecimentos embasada pela crítica social, consoante a dialética entre teoria e prática. Essa construção de práticas inclusivas compreende, portanto, um modo de agir/fazer deflagrado por processos formativos pela via da pesquisa, o que, de acordo com Zeichner (1998, p. 229), consiste em "[...] ultrapassar a linha divisória entre os professores e os pesquisadores acadêmicos".

As crenças simétricas de que todo "teórico" não é prático e de que todo "prático" não é teórico são, portanto, completamente errôneas [...]. As "teorias" não são corpos de conhecimento que podem gerar-se num vazio prático, como tampouco o ensino é um trabalho do tipo robóticomecânico, alheio a toda reflexão teórica. (Carr; Kemmis, 1988, p. 126, tradução nossa). ${ }^{1}$

Quando da proposição de um processo de pesquisa-ação que procura colocar os gestores dos setores de educação especial como autores do processo de construção de conhecimentos, aprofundam-se concepções teórico-conceituais sobre práticas de formação continuada na articulação constante com as práticas vivenciadas. Esse movimento permite uma "[...] aproximação entre teoria e prática, entre conhecimento e interesse, sem priorizar um em detrimento do outro" (Habermas, 2002 apud Almeida, 2010, p. 33).

\footnotetext{
"Las creencias simétricas de que todo 'lo teórico' es no práctico y todo 'lo práctico' es no teórico son, por tanto, completamente erróneas [...]. Las 'teorías' no son cuerpos de conocimiento que puedan generarse en un vacío práctico, como tampoco la enseñanza es un trabajo de tipo robótico-mecánico, ajeno a toda reflexión teórica".
} 


\section{Contextualizando o objeto do estudo}

Este artigo aborda movimentos constituídos durante o processo de uma pesquisa-ação colaborativo-crítica, realizado por uma universidade em parceria com secretarias municipais e estaduais de educação do Espírito Santo. Foram convidados gestores públicos de educação especial (técnicos/ coordenadores responsáveis pelo setor) de três superintendências regionais de educação (SRE) e dos municípios sob sua jurisdição. ${ }^{2}$

Os gestores de três SRE das regiões sul e serrana foram convidados a integrar um grupo de estudo-reflexão com vistas a alcançar coletivamente uma proposta de formação que criasse condições para que os saberes e as demandas dos profissionais da área fossem visibilizados. Esse processo pôde ser organizado em três percursos: encontros realizados na universidade; encontros virtuais; e encontros nas SRE. Os caminhos percorridos resultaram na construção e no processo de implementação, pelos gestores da Regional Serrana, da proposta de uma política pública para formação continuada.

O primeiro contato com os gestores ${ }^{3}$ ocorreu nas SRE, quando se formaram grupos focais (Gatti, 2005). Havia, nesse momento, a intenção de propiciar o engajamento dos gestores diante da proposta. Recorreu-se a acontecimentos relacionados ao movimento de pesquisas anteriores sobre a educação especial nos municípios, com objetivo de mapear os processos de continuidades e rupturas na gestão de educação especial nas secretarias municipais de educação e nas superintendências regionais de ensino. Praticamente todos aceitaram o convite, talvez sem compreender naquele momento que se trataria de um processo de pesquisa-formação pela via da construção conjunta do conhecimento.

Em dezembro de 2013, iniciaram-se os encontros do grupo de estudoreflexão na universidade. Esse primeiro encontro foi, sem dúvida, um tanto desafiador, tanto para quem estava propondo essa outra dinâmica de pesquisa-formação como para os gestores. Inicialmente, no grupo de pesquisadores-acadêmicos, houve dificuldade em organizar esses encontros. Os acadêmicos, sempre acostumados com as metodologias e estratégias técnicas, pouco dialógicas, agora se deparavam com a proposta de construir uma comunidade de pesquisadores em conjunto com os gestores e, para isso, era preciso elaborar formas de mediação que propiciassem a participação de todos, em todo o processo (Habermas, 2004).

No início, os gestores indagavam: "mas o que vamos estudar aqui?"; "quais conteúdos vamos discutir?"; "quais os textos vocês vão nos indicar?";

No estado do Espírito Santo, os municípios se organizam em onze superintendências regionais de educação, compreendendo o sistema estadual de ensino e os sistemas municipais que não possuem autonomia municipal.

3 Vale destacar que muitos dos gestores já participavam de estudos de natureza colaborativa na universidade. "quais atividades teremos que fazer?" A resposta era que, naquele primeiro dia, seriam discutidos os caminhos a percorrer. Procurava-se exercitar uma premissa fundamental na organização dos processos de conscientização e aprendizagem, propostos por Habermas (1987), que versa sobre a liberdade do discurso, ou seja, sobre uma comunicação aberta e democrática.

Na continuidade do percurso, foram promovidos encontros mensais presenciais e encontros via plataforma Moodle $\AA$, que, conforme Sabbatini (2007), "[...] é uma plataforma de aprendizagem a distância baseada em 
software livre. É um acrônimo de Modular Object-Oriented Dynamic Learning Environment (ambiente modular de aprendizagem dinâmica orientada a objetos)". Objetivava-se a análise e reflexão das propostas de formação continuada: estudo e aprofundamento de questões teóricoconceituais; planejamento e reflexão sobre o processo de pesquisa-ação e a formação com os gestores, conciliando demandas e exercitando negociações entre entendimentos e anseios.

Na sequência, deu-se início aos encontros nas SRE, etapa em que as superintendências e os municípios jurisdicionados elaboraram seus projetos de políticas públicas de formação continuada. A sistematização aconteceu no período de julho a novembro de 2014 e foi como uma mola propulsora da aprendizagem do grupo, no sentido de organizar sua própria aprendizagem, considerando o processo de autorreflexão sistematizada. A partir daí, os gestores passaram a se organizar em um movimento que tomou diferentes contornos em cada regional.

Diante do desafio de sistematizar os projetos de políticas públicas de formação continuada, considerando as realidades locais, esse grupo foi construindo sua autonomia no processo de pesquisa-ação. Esse processo possibilita a determinado grupo sua constituição em comunidades autocríticas de pesquisadores (Carr; Kemmis, 1988), preocupados com os processos de conscientização e com as transformações de suas concepções e práticas.

Neste texto, procurou-se registrar o movimento de construção dos projetos nas SRE, focalizando o processo de discussão e produção do grupo de gestores da Regional de Afonso Cláudio. ${ }^{4}$ O percurso do grupo é pautado pela busca do diálogo no processo de partilha das demandas e de construção de uma proposta para toda a Região Serrana que concilie objetivos comuns e peculiaridades de cada município. Envolver superintendente regional de educação e secretários de educação fortalece uma proposta de trabalho coletivo, por meio da qual é possível garantir uma política de formação continuada que contemple a perspectiva da inclusão.

Nesse contexto, a presente análise estabelece um diálogo entre autores da literatura científica e autores do contexto (os gestores da Regional Afonso Cláudio). Pela tessitura da discussão, intenta-se refletir a trajetória constitutiva desse grupo de gestores no que se refere às implicações da pesquisa-ação na construção da política de formação continuada. A premissa baseia-se em Habermas (2003).

\footnotetext{
No lugar do sujeito solitário, que se volta para objetos e que, na reflexão, se toma a si mesmo por objeto, entra não somente a ideia de um conhecimento linguisticamente mediatizado e relacionado com o agir, mas também o nexo da prática e da comunicação quotidianas, no qual estão inseridas as operações cognitivas que têm desde a origem um caráter intersubjetivo e ao mesmo tempo cooperativo. (Habermas, 2003, p. 25).
}

Obtém-se, assim, a construção do conhecimento com o outro. A produção do grupo embasou a problematização de pressupostos sobre a potência dos grupos autogestores na produção de conhecimentos sobre a

\footnotetext{
4 São sete os municípios que compõem a regional (Afonso Cláudio, Conceição do Castelo, Laranja da Terra, Brejetuba, Venda Nova do Imigrante, Domingos Martins e Santa Maria de Jetibá).
} 
formação continuada de profissionais da educação, em especial, a formação de gestores públicos de educação especial. Utilizaram-se como ferramentas de pesquisa os diários de campo de encontros realizados na universidade; os relatórios das reuniões realizadas pelos gestores nas regionais; o mapeamento (formulário) das formações ofertadas pelos municípios ou pelas superintendências nos anos de 2014; a transcrição de gravações em vídeo; e o projeto parcial de formação continuada, elaborado pelos gestores.

\section{Os contornos das políticas educacionais e suas implicações para a formação continuada dos profissionais da educação}

O debate acerca dos processos de escolarização dos alunos com deficiência, transtornos globais do desenvolvimento e altas habilidades intensificou-se nas últimas décadas em diversos países. Os diversos movimentos de luta pela inclusão social e escolar dessa população ganharam fôlego a partir dos anos 1990 por meio de acordos e políticas educacionais internacionais, como se pode observar na Declaração Mundial sobre Educação para Todos (1990), na Declaração de Salamanca (1994) e na Convenção da Guatemala (1999), que influenciaram a formulação das políticas públicas de educação inclusiva em todo mundo.

No fluxo dos movimentos globais, no Brasil observa-se que as mudanças que ocorreram a partir da década de 1980 na legislação brasileira Constituição Federal (Brasil, 1988) e Lei de Diretrizes e Bases da Educação (Brasil, 1996) -legitimaram o direito à escolarização do aluno público-alvo da educação especial com ingresso no ensino comum, dando nova tratativa aos conceitos e às concepções na área da educação. A Lei no 9.394 de Diretrizes e Bases da Educação Nacional, de 20 de dezembro de 1996, passou a ter um capítulo dedicado à modalidade da educação especial. A redação dada pela Lei $n^{\circ} 12.796$, de 2013, dispõe:

Entende-se por educação especial, para os efeitos desta Lei, a modalidade de educação escolar oferecida preferencialmente na rede regular de ensino, para educandos com deficiência, transtornos globais do desenvolvimento e altas habilidades ou superdotação. (Brasil, 2013).

No entanto, pode-se dizer que a materialização dessa e de outras ações legais se dará por meio da instituição de políticas públicas visando à formação continuada dos educadores, à articulação entre educação especial e ensino comum, à reestruturação arquitetônica das escolas e à ressignificação do currículo, das práticas pedagógicas e da avaliação. Para isso, a Resolução CNE/CEB n ${ }^{\circ}$ 2, de 11 de setembro de 2001, que institui Diretrizes Nacionais para a educação especial na educação básica, destaca em seu artigo $2^{\circ}$ :

Art. $2^{\circ}$ Os sistemas de ensino devem matricular todos os alunos, cabendo às escolas: organizar-se para o atendimento aos educandos com necessidades educacionais especiais, assegurando as condições necessárias para uma educação de qualidade para todos. (Brasil. CNE. CEB, 2001, p.1). 
Recentemente, a Política Nacional de Educação Especial na perspectiva da Educação Inclusiva (MEC/SEESP/2008) ressalta que "[...] as políticas educacionais não alcançaram o objetivo de levar a escola comum a assumir o desafio de atender as necessidades educacionais de todos os alunos" (Brasil. MEC, 2008, p. 15). As políticas de educação especial passaram a focalizar o atendimento educacional especializado (AEE), que disponibiliza serviços e recursos, com atividades diferenciadas daquelas realizadas na sala regular, portanto, não substitutivas à escolarização.

O conjunto das diretrizes aportadas pela legislação, a partir de 2008, motiva pesquisadores, gestores e professores a problematizar essas e outras questões trazidas pelos documentos legais, considerando a organização dos sistemas de ensino, das escolas, bem como das políticas de formação de professores que procuram constituir práticas pedagógicas inclusivas.

Em 2008 delimita-se o alunado e restringem-se os modos de escolarização, basicamente, ao atendimento educacional especializado. Assim, o que significa o foco no AEE? Que consequências tem/terá para o processo de inclusão na escola comum? Onde afinal queremos incluir o aluno? Que espaços precisam ser sustentados? Quem pode contribuir para a sustentabilidade desses espaços? (Almeida, 2012, p.5).

As discussões, que emergiram nesse período e chegam aos dias atuais, conduzem a diferentes questionamentos, contudo é possível considerar que o desafio para a formação do profissional da educação se mantém diante do objetivo de "[...] garantir a oferta de educação inclusiva, vedada a exclusão do ensino regular sob alegação de deficiência e promovida a articulação pedagógica entre o ensino regular e o atendimento educacional especializado", conforme estratégia 4.8 do Plano Nacional de Educação - PNE (Brasil, 2014). Ao refletir sobre os aspectos que constituem a elaboração e a implementação das políticas educacionais inclusivas, há consenso de grande parte dos engajados nesse debate sobre a necessidade de formação profissional adequada que atenda às especificidades do público-alvo da educação especial, tão heterogêneo e pertencente a contextos diversos.

Quanto ao público-alvo, as definições devem ser contextualizadas e não se esgotam na mera categorização e especificações atribuídas a um quadro de deficiência, transtornos, distúrbios e aptidões. Considera-se que as pessoas se modificam continuamente, transformando o contexto no qual se inserem, independentemente de etnia, gênero, idade, deficiência, condição social ou qualquer outra situação. O princípio da educação inclusiva deverá ser garantido nas instituições escolares para que fique assegurado a cada aluno o direito de acesso e permanência, visto que o aluno é sujeito de direito e foco de toda ação educacional (Espírito Santo, 2011).

Tonoli et al. (2014, p. 10), na justificativa da proposta para o Projeto Político de Formação Continuada em Educação Especial em face do processo de inclusão escolar da Regional Serrana, afirmam que

[...] vários movimentos vêm acontecendo nas escolas, [porém observase] [...] a ausência ou descontinuidade de políticas efetivamente propostas pelos governos, o que evidencia avanços e retrocessos históricos que apontam para a necessidade de elaboração das Diretrizes 
Estaduais da Educação Especial na Educação Básica e Profissional que se constituem e dão alicerce para uma política de Estado.

É muito complexo atender plenamente à legislação, mas os documentos que norteiam a educação especial, em uma dinâmica intensa nas últimas décadas, têm proporcionado reflexões, tensões, críticas e muita criatividade por parte dos profissionais da educação na tentativa de cumpri-la. Para o Espírito Santo, as dificuldades não são muito diferentes, pois a demanda consiste em assegurar o atendimento, por meio dessas mesmas normas públicas, e em garantir as condições necessárias a uma educação de qualidade para todos os sujeitos da educação.

Dessa forma, existe um panorama em que a formação continuada tem papel importante no processo da inclusão escolar, visto que esse movimento requer profissionais qualificados para sua efetivação e cumprimento legal. A democratização das escolas aponta para o dever de esse espaço assumir a formação de seus profissionais.

Gatti (2008, p. 57) esclarece que, nos últimos dez anos,

[...] cresceu geometricamente o número de iniciativas colocadas sob o grande guarda-chuva do termo "educação continuada". As discussões sobre o conceito de educação continuada nos estudos educacionais não ajudam a precisar o conceito, e talvez isso não seja mesmo importante, aberto que fica ao curso da história.

Assim, há multiplicidade de iniciativas desenvolvidas em diferentes modalidades metodológicas, visando a variados tipos de formação, com foco em professores de diversos níveis de ensino e especialidades.

A formação continuada é significada como desafio para todos. Os gestores entendem sua responsabilidade por fomentá-la, no entanto, há dificuldades tanto sobre o processo, quanto sobre a garantia de condições concretas. Por outro lado, não se colocam em um "lugar de poder", de maneira que possam viabilizar a formação em diferentes contextos. (Vieira et al., 2011, p. 6).

Como assinalam Vieira et al. (2011), os gestores têm assumido a responsabilidade e os desafios de fomentar e implementar a formação continuada em estados e municípios. Em estudos recentes, realizados no cenário capixaba (Gonçalves, 2008; Pantaleão, 2009; Jesus, 2012; Jesus; Almeida, 2014; Almeida, 2016), tem-se apostado na compreensão e transformação das políticas existentes, mediante autorreflexão organizada por grupos de estudo-reflexão, os quais possibilitam contribuir para o avanço do conhecimento sobre a formação dos profissionais, em especial na gestão pública em educação especial.

A fim de compreender os processos de formação continuada por meio de grupos de estudo-reflexão entre gestores públicos municipais e estaduais de educação especial e pesquisadores da universidade, para elaboração de proposta de política para formação continuada em uma perspectiva inclusiva, preconiza-se a necessidade de construção de uma política de formação continuada, conforme a estratégia 16.2 do PNE: "Consolidar 
política nacional de formação de professores e professoras da educação básica, definindo diretrizes nacionais, áreas prioritárias, instituições formadoras e processos de certificação das atividades formativas" (Brasil, 2014).

Embora essa ideia exista desde a Constituição de 1988, recentemente o PNE reitera a necessidade de concretização do regime de colaboração entre instituições públicas de educação superior de forma orgânica, articulada às políticas de formação dos estados, do Distrito Federal e dos municípios, no planejamento e dimensionamento da demanda por formação continuada. Se, por um lado, a ênfase nos processos de colaboração entre as instituições públicas ganhou destaque nas últimas décadas, por outro, um ponto relevante se evidencia entre as concepções ideológicas que subjazem às políticas, bem como entre as condições concretas para sua efetivação: Piolli, Silva e Heloani (2015) argumentam que o modelo gerencial implantado no campo educacional nas escolas e universidades alinha-se às metas do PNE, quais sejam individualismo e competitividade nas relações de trabalho. Torna-se essencial a reflexão de Ball (2001, p. 100):

[...] até que ponto estamos a assistir ao desaparecimento gradual da concepção de políticas específicas do Estado Nação nos campos econômico, social e educativo e, concomitantemente, o abarcamento de todos estes campos numa concepção única de políticas para a competitividade econômica, ou seja, o crescente abandono ou marginalização (não no que se refere à retórica) dos propósitos sociais da educação.

O avanço do modo produtivista de mercado, que sustenta as políticas públicas educacionais desde a década de 1990 até hoje, ancora-se na racionalidade instrumental, em que os sujeitos, a partir dos seus interesses individuais, exercem influências uns sobre os outros, alimentando, assim, a desvalorização da ética e o esvaziamento da política e dos espaços democráticos, em favor da gestão. "O gerencialismo pretende constituir-se como ciência lastreada nas ciências exatas e substituir todo pensamento considerado não utilitário como pouco eficiente. Há, portanto, predomínio da razão instrumental" (Piolli; Silva; Heloani, 2015, p. 592).

Considerando que os gestores públicos de educação especial atuam diretamente nos contextos de produção do texto e da prática das políticas públicas de formação continuada (Ball; Bowe, 1992 apud Mainardes, 2006), seja ocupando o lugar de elaboradores, seja ocupando o lugar de agentes da política, procurou-se construir, pela via da pesquisa-ação, outros modos de conceber as políticas públicas educacionais, por meio da racionalidade comunicativa.

É importante acreditar em uma política pública de formação continuada que desafie gestores e professores como produtores de conhecimentos, ou seja, que esteja "[...] sujeita à interpretação e recriação e onde a política produz efeitos e consequências que podem representar mudanças e transformações significativas na política original" (Bowe et al., 1992 apud Mainardes, 2006, p. 53). 


\section{O discurso dos gestores públicos de educação especial da Regional de Afonso Cláudio no movimento de construção da proposta política de formação continuada}

\begin{abstract}
[...] nós optamos pela questão de estarmos desenvolvendo uma proposta política juntos, como um todo. Todos os municípios estarão juntos nesse desenvolvimento da nossa proposta política de formação continuada. (informação verbal). ${ }^{5}$
\end{abstract}

No movimento do processo formativo, observou-se que uma das superintendências se destacava em relação às demais regionais, apresentando mais sugestões oriundas de encontros entre os municípios sob sua jurisdição. Essa passou, então, a ser o objeto de análise, pois demonstrava a intenção de ter a formação continuada como um instrumento de política para a regional.

Os desdobramentos suscitados no grupo de estudo-reflexão nos remetem à formulação de Habermas sobre o agir comunicativo, que se refere à interação de pelo menos dois sujeitos capazes de se expressar por meio da linguagem e que, por meios verbais ou não, estabelecem uma relação. Sendo assim, importante se faz apresentar esse conceito: "[...] o agir comunicativo são aquelas interações mediadas linguisticamente nas quais todos os participantes prosseguem objetivos ilocucionários, e somente objetivos ilocucionários, com seus atos mediadores de comunicação". (Habermas apud Bannell, 2013, p. 70).

Para Habermas (2004, p. 106), "todo agir é intencional" e contém, em seu bojo, uma pretensão de validade que é expressa no ato da fala. No movimento do grupo, verificou-se, por meio dos diálogos, pela via da comunicação, que quem fala é o dono da comunicação, pois exibe consigo sua intencionalidade e sua vontade, movimentando a essência do agir comunicativo. Dessa forma, a racionalidade comunicativa leva em consideração as condições que tornam válido um ato de fala, a pretensão de validade levantada pelo falante e a garantia de seu cumprimento.

Assim, o que o teórico propõe está presente no grupo de estudoreflexão e é evidenciado na fala da gestora, que aponta a intencionalidade na ação:

[...] nós estamos com intenção, nossa intenção lá em Santa Maria é de construir esse projeto junto com todos os outros setores, um único projeto e não o ensino fundamental vai fazer um projeto de formação, a educação infantil, não. Nós vamos fazer um único, abrangendo todas as modalidades. (informação verbal). ${ }^{6}$

Nesse movimento do grupo e da superintendência, o que se nota é a postura das gestoras que querem construir uma proposta contínua de formação para os municípios, por meio da qual o próprio município reconheça essa necessidade e a inclua na política municipal de forma perene. No movimento do grupo de estudo-reflexão aconteceram vários encontros para aprofundar estudos e debates de literatura científica, bem como de referenciais teórico-metodológicos. Nesse contexto, partindo da 
necessidade do grupo em materializar a proposta de política de formação continuada, foi preciso entender "como" formular uma política de formação e "qual" perspectiva de formação continuada era sustentada pelos gestores. Observa-se, nessa ação, a presença do agir comunicativo, pois os atores do processo participam com conhecimentos trazidos de seu locus de atuação como profissionais da educação especial, buscando o entendimento pela via do diálogo.

A formulação do conceito de formação continuada seguiu uma categorização em que o grupo de gestores construiu um entendimento baseado nas seguintes questões: de onde ela advém; como deve ser organizada; em que consiste; o que pretende; e qual é o seu objetivo final. Consequentemente, o conceito de formação continuada teve a seguinte redação, a mesma empregada na elaboração da proposta:

[...] a formação continuada é um processo que se configura a partir da inserção e vivência profissional, decorrente de demandas e reflexões do cotidiano a partir dos desafios oriundos da prática. Em sua organização/ oferta devem ser consideradas as experiências e necessidades dos profissionais às quais ela se destina. Ela pode ser ofertada em horário de trabalho ou fora dele. (informação verbal). ${ }^{7}$

A consolidação do conceito de formação continuada demanda outras reflexões e a formulação de outros conceitos fundamentais. Esse processo foi sendo organizado por meio do compromisso assumido com os gestores para o desenvolvimento de uma pesquisa que fomentasse uma formação continuada dos professores, sustentada pela crítica social, na dialética entre teoria e prática.

Colocar saberes e concepções em xeque e construir novos conceitos por meio da reflexão e da crítica partilhada passou a ser "ferramenta" que ancorou os momentos de pesquisa-formação entre os gestores e acadêmicos, ou seja, foi possível

[...] criar comunidades críticas de professores que, por meio de uma investigação participativa concebida como análise crítica, se encaminhassem à transformação das práticas educativas, dos valores educativos e, em última instância, das estruturas sociais e institucionais. (Benedito, 1988, p. 14, tradução nossa).

Importante se faz a observação sobre esses processos e tais conceitos de formação continuada e pesquisa-ação, uma vez que, nas discussões, os gestores entraram em entendimento ao se apropriarem daquilo que é importante para que a formação continuada seja promovida adequadamente. Tais ações vão ao encontro do proposto por Habermas (1987 apud Almeida, 2010, p.147), posto que "[...] a apropriação de conhecimento e mudanças de práticas" advém da parceria e do entendimento dos participantes em contexto.

Ainda pela via da reflexão crítica, os grupos buscaram investigar a si mesmos para, então, elaborar um projeto político de formação continuada de toda a região. Assim, debateram a temática da formação continuada, da intersetorialidade e de descentralização para contextualizar a educação
7 Trecho extraído do Diário de Campo de maio de 2014. 
especial e, posteriormente, as instruções para elaboração do projeto de formação. No diálogo a seguir, destacam-se alguns pontos de discussão que foram fundantes para o início da elaboração da proposta:

Como os gestores de educação especial dos municípios têm pensado e dialogado, com suas secretarias, sobre a formação continuada para 2015 ?

- [...] Como tem sido a avaliação e o acompanhamento dos alunos com deficiência no ensino fundamental, uma vez que temos constatado a falta de alfabetização em grande parte dos alunos no ensino médio?

- Como proceder com a terminalidade? (informação verbal). ${ }^{8}$

As gestoras apresentaram os objetivos para a elaboração do projeto político:

Fortalecer as práticas pedagógicas e parcerias; compreender o lugar onde os alunos vivem suas experiências pedagógicas; estudar e aplicar a pesquisa-ação como forma de implementar a ação colaborativa e realizar formação continuada de forma unificada em toda a regional. (informação verbal). ${ }^{9}$

A partir da fala da gestora, percebe-se uma compreensão da proposta de formação contínua partindo da colaboração entre os entes federados e reafirmando o preceito do art. $62, \S 1^{\circ}$, que diz: "A União, o Distrito Federal, os estados e os municípios, em regime de colaboração, deverão promover a formação inicial, a continuada e a capacitação dos profissionais de magistério" (Brasil, 1996). Ressalta-se que, no processo de criação da proposta, os municípios que não estiveram presentes nas reuniões também foram incluídos, considerando que o sujeito público da educação especial é aluno da regional, não só do município. Como destaca a gestora,

[...] fizemos um convite especial para Venda Nova do Imigrante e Brejetuba, por quê? Porque nós precisamos pensar em um trabalho para região; mesmo que não tenham representações de Venda Nova do Imigrante e Brejetuba, o nosso grupo aqui entende que vocês fazem parte da regional. (informação verbal). ${ }^{10}$

Na proposição da política de formação continuada, os gestores viram a necessidade de envolver os secretários municipais na discussão do trabalho, considerando as fragilidades e as potencialidades da regional. Dessa forma, organizaram um encontro na Superintendência de Afonso Cláudio com os secretários dos municípios sob sua jurisdição e apresentaram as pretensões e as justificativas da proposta.

[...] É uma política de formação para a regional. Por quê? Porque nós precisamos fazer formação continuada dos nossos profissionais, em educação especial, que é o motivo da nossa reunião aqui hoje. E todo profissional precisa de formação (informação verbal). ${ }^{11}$

Houve, ainda, a discussão sobre a realidade de cada um dos municípios, bem como a diligência coletiva para responder tanto às demandas específicas como às da regional como um todo. Apresentou-se, assim, 
um diagnóstico do público-alvo da educação especial atendido, do tipo de atendimento e do local em que se dava o atendimento.

[...] Atualmente, no censo escolar, são 959 alunos com deficiência [...] destes 172 alunos, que o Município de Afonso Cláudio tem, a APAE Afonso Cláudio atende 26, porque as APAE elas têm o CAEE, que é o Centro de Atendimento Educacional Especializado, então eles ofertam o atendimento educacional especializado. Destes 26, 24 são da rede municipal, sendo que 2 são de Laranja da Terra, porque Laranja da Terra não tem APAE, e 22 são do Município de Afonso Cláudio, e 2 são meus da rede estadual. Certo? Então nós temos 172 alunos e a APAE atende apenas 26. (informação verbal). ${ }^{12}$

$\mathrm{Na}$ informação anterior, a gestora expôs parte do diagnóstico apresentado que proporcionou os encaminhamentos possíveis de uma política de formação continuada dos profissionais da educação, em uma perspectiva inclusiva. Esse movimento resultou, pois, no entendimento dos gestores de que os secretários municipais precisariam conhecer a proposta, antecipadamente, aprová-la e formalizá-la legalmente:

Foi de extrema importância a participação dos secretários na construção deste diálogo e deste projeto, pois os gestores de educação especial não teriam condições de assumir as fragilidades sem o aval dos mesmos, e estas foram apresentadas por ambas as partes, o que ao mesmo tempo foi definindo as possibilidades de parcerias para a política de formação continuada em educação especial a ser constituída na Regional Serrana. (informação verbal). ${ }^{13}$

Após a apresentação, os secretários dialogaram sobre os dados apresentados e sobre a possibilidade de se estabelecer uma política pública de formação continuada na regional.

[...] o que temos que pensar é: uma política de governo [...] que envolva algo mais constante. Mesmo as pessoas não estando aqui, que ela continue, que prossiga. Este é um aspecto que temos que pensar, até em termos de registro de uma política, um projeto, seja a sistematização de uma política, mas que já tenha começado e terá continuidade. (informação verbal). ${ }^{14}$

Os secretários presentes firmaram um compromisso com a proposta de política apresentada, considerando ser de extrema importância a participação de cada um na construção de diálogos para a elaboração do projeto. Torna-se relevante a seguinte fala:

[...] Eu só acredito em evolução em formação continuada. Eu não acredito em palestra. Vamos fazer palestra! Palestra é igual a..., você paga, assiste e amanhã já esqueceu tudo. Então eu só acredito em formação continuada, e nesse ponto eu bato palmas, para a proposta. [...] Então antes de encerrar, eu quero dizer: sim! (informação verbal). ${ }^{15}$

Esse momento revela a necessidade de envolvimento dos secretários no processo, conforme fala da gestora: "[...] os gestores de educação especial não teriam condições de assumir as fragilidades sem o aval dos secretários". Desse modo, os municípios com os secretários chancelam a parceria na

\footnotetext{
12 Transcrição do encontro na Superintendência de Afonso Cláudio, realizado em 10 de outubro de 2014 .

13 Transcrição do encontro na Superintendência de Afonso Cláudio, realizado em 10 de outubro de 2014 .

14 Transcrição do encontro na Superintendência de Afonso Cláudio, realizado em 10 de outubro de 2014.

15 Transcrição do encontro na Superintendência de Afonso Cláudio, realizado em 10 de outubro de 2014.
} 
proposta de política de formação continuada para a regional, uma vez que as questões de formação precisam acontecer para além das pessoas e dos cargos políticos, requerendo, pois, caráter oficial.

Por fim, no mês de novembro de 2014, aconteceu o Seminário de Gestão em Educação Especial e Formação Continuada em uma Perspectiva Inclusiva, com o objetivo de dialogar sobre a proposta desenvolvida pela regional. $\mathrm{Na}$ ocasião, a gestora de Afonso Cláudio esclareceu que o objetivo na elaboração proposta foi dialogar com gestores, pesquisadores, estudantes, superintendentes regionais e secretários municipais de educação sobre a organização e a participação de todos na construção do projeto.

Desse modo, as concepções que perpassam a construção de políticas de formação continuada para os profissionais da educação especial decorrem de discussões e reflexões dos gestores com relação à própria formação, quando há clara preocupação em preencher as lacunas, com vistas ao desenvolvimento profissional e pessoal de professores.

\section{Considerações finais}

Este artigo analisou as contribuições da pesquisa-ação para a elaboração de projeto político de formação continuada de profissionais na perspectiva da inclusão escolar, da qual se encarregaram os gestores públicos de educação especial da Superintendência Regional de Afonso Cláudio, bem como dos municípios sob sua jurisdição, por meio de grupos de estudo-reflexão, em uma perspectiva colaborativo-crítica. De modo específico, também dialogou com conceitos e concepções expressas no percurso e no projeto elaborado, sob a ótica da teoria do agir comunicativo de Habermas.

No movimento de constituição da proposta dos processos de formação continuada, observou-se que a especificidade de cada município do setor regional não se apresentou como uma impossibilidade para a sistematização de um projeto político em conjunto. Nesse contexto, este estudo demonstra que a colaboração entre profissionais e pesquisadores ativos nas práticas educativas pode se configurar como possibilidade de construção de projetos que atendam a várias localidades, independentemente das especificidades locais, como sugerem Carr e Kemmis (1988).

O projeto construído tem uma peculiaridade: embora nem todos os municípios pertencentes à regional estivessem no movimento da pesquisa-formação, todos foram convidados pelos gestores para o processo de elaboração da proposta e, assim, passaram a integrar o grupo de estudo-reflexão.

Neste artigo, buscaram-se, com gestores públicos de educação especial, os princípios do diálogo, da colaboração e da autorreflexão crítica no processo de "formar formando-se" (Pantaleão, 2009, p. 99), essencial à própria dinâmica da pesquisa-ação colaborativo-crítica. Os gestores, ao construírem propostas de formação continuada para os profissionais de suas redes de ensino, desenvolveram sua própria formação, na qual os 
princípios do diálogo, da autorreflexão crítica e da colaboração sustentaram a dinâmica em sentido duplo.

Assim, o percurso constituído por esse grupo de gestores públicos de educação especial mostra a possibilidade de construção de políticas educacionais que se afaste da lógica instrumental disseminada com o avanço do modo produtivista de mercado. Os gestores concretizaram outros modos de conceber o espaço de produção de políticas públicas de educação especial na perspectiva da inclusão escolar, pela via da pesquisa-ação colaborativocrítica, pautada pela racionalidade comunicativa, que promove diálogo e entendimento.

\section{Referências bibliográficas}

ALMEIDA, M. L. Uma análise da produção acadêmica sobre os usos da pesquisa-ação em processos de inclusão escolar: entre o agir comunicativo e o agir estratégico. 2010. $234 \mathrm{f}$. Tese (Doutorado em Educação) - Programa de Pós-Graduação em Educação, Universidade Federal do Espírito Santo, Vitória, 2010.

ALMEIDA, M. L. A construção de conhecimentos na/pela pesquisaação: implicações para a prática pedagógica em educação especial na perspectiva da inclusão. In: ENCONTRO NACIONAL DE DIDÁTICA E PRÁTICAS DE ENSINO, 16., 2012, Campinas. Anais... Campinas: ENDIPE, 2012. Disponível em: <http://www.infoteca.inf.br/endipe/smarty/ templates/arquivos_template/upload_arquivos/acervo/docs/3353b.pdf > Acesso em: 21 abr. 2017.

ALMEIDA, M. L. Desafios e possibilidades na formação continuada de profissionais da educação: trajetória de um grupo de estudo-reflexão. In: MENDES, E. G.; ALMEIDA, M. A. (Org.). Inclusão escolar e educação especial no Brasil: entre o instituído e o instituinte. v. 1. Marília: ABPEE, 2016. p. 169-190.

BALL, S. Diretrizes políticas globais e relações políticas locais em educação. Currículo sem Fronteiras, v. 1, n. 2, p. 99-116, jul./dez. 2001. Disponível em: <http://www.curriculosemfronteiras.org/ vol1iss2articles/ball.pdf > Acesso em: 21 abr. 2017.

BARBIER, R. A pesquisa-ação. Tradução de Lucie Didio. Brasília: Líber Livro, 2002 .

BANNELL, R. I. Habermas e a educação. 2. ed. Belo Horizonte: Autêntica, 2013. 
BENEDITO, V. Prólogo. In: CARR, W.; KEMMIS, S. Teoría crítica de la enseñanza: la investigación-acción en la formación del profesorado. Tradução de J. A. Bravo. Barcelona: Martinez Roca, 1988. p. 11-15.

BRASIL. Constituição (1988). Constituição da República Federativa do Brasil. Brasília, 1988.

BRASIL. Lei no 9.394, de 22 de dezembro de 1996. Estabelece as diretrizes e bases da educação nacional. Diário Oficial da União, Brasília, 23 dez. 1996. Seção 1, 27833.

BRASIL. Lei $\mathrm{n}^{\circ}$ 12.796, de 4 de abril de 2013. Altera a Lei no 9.394, de 20 de dezembro de 1996, que estabelece as diretrizes e bases da educação nacional, para dispor sobre a formação dos profissionais da educação e dar outras providências. Diário Oficial da União, Brasília, 5 abr. 2013. Seção 1, p. 1.

BRASIL. Lei no 13.005, de 25 de junho de 2014. Aprova o Plano Nacional de Educação - PNE e dá outras providências. Diário Oficial da União, Brasília, 26 jun. 2014. Seção 1, p. 1.

BRASIL. Conselho Nacional de Educação (CNE). Câmara da Educação Básica (CEB). Resolução CNE/CEB n 2, de 11 de setembro de 2001. Institui diretrizes nacionais para a educação especial na educação básica. Diário Oficial da União, Brasília, 14 set. 2001. Seção 1, p. 39.

BRASIL. Ministério da Educação (MEC). Política Nacional de Educação Especial na perspectiva da educação inclusiva. Brasília, 2008. Disponível em: <http://portal.mec.gov.br/ arquivos/pdf/ politicaeducespecial.pdf > Acesso em: 10 abr. 2016.

CARR, W.; KEMMIS, S. Teoría crítica de la enseñanza: la investigaciónacción en la formación del profesorado. Tradução de J. A. Bravo. Barcelona: Martinez Roca, 1988.

CONVENÇÃO interamericana para a eliminação de todas as formas de discriminação contra as pessoas portadoras de deficiência. 1999. Disponível em: <eduardobarbosa.com/textos/ver/3/26/0>. Acesso em: 27 abr. 2018

ESPIRITO SANTO. Diretrizes da educação especial na educação básica e profissional para a rede estadual de ensino do Espírito Santo. 2. ed. 2011. Disponível em: < http://sedu.es.gov.br/Media/sedu/pdf\%20e\%20 Arquivos/Diretrizes\%20da\%20Ed.\%20Especial\%20no\%20ES\%20\%20 -\%20Sedu.pdf> Acesso em: 16 nov. 2015. 
FRANCO, M. A. S. Apresentação da sessão Em foco: A pesquisa-ação e a prática docente. Educação e Pesquisa, São Paulo, v. 31, n. 3, p. 439-443, dez. 2005a.

FRANCO, M. A. S. Coordenação pedagógica: uma práxis em busca de sua identidade. Educativa, Goiânia, v. 8. n. 1, p. 125-138, jan./jul. 2005b.

FRANCO, M. A. S. Práticas pedagógicas de ensinar-aprender: por entre resistências e resignações. Educação e Pesquisa, São Paulo, v. 41, n. 3, p. 601-614, jul./set. 2015.

GATTI, B. A. Grupo focal na pesquisa em ciências sociais e humanas. Brasília: Líber Livro, 2005.

GATTI, B. A. Análise das políticas públicas para formação continuada no Brasil, na última década. Revista Brasileira de Educação, Rio de Janeiro, v. 13, n. 37, p. 57-70, jan./abr. 2008.

GONÇALVES, A. F. S. As políticas públicas e a formação continuada de professores na implementação da inclusão escolar no município de Cariacica. 2008. 356 f. Tese (Doutorado em Educação) - Programa de Pós-Graduação em Educação, Universidade Federal do Espírito Santo, Vitória, 2008.

HABERMAS, J. Teoría de la acción comunicativa: racionalidad de la acción y racionalización social. v. 1. Versión de Manuel Jimenez Redondo. Madrid: Taurus, 1987.

HABERMAS, J. Consciência moral e agir comunicativo. 2. ed. Rio de Janeiro: Tempo Brasileiro, 2003.

HABERMAS, J. Verdade e justificação: ensaios filosóficos. Tradução de Milton Camargo Mota. São Paulo: Loyola, 2004.

JESUS, D. M. Vozes e narrativas na ação grupal: trajetórias de formação de professores-pesquisadores na perspectiva da inclusão escolar. In: JESUS, D. M. et al. Inclusão, práticas pedagógicas e trajetórias de pesquisa. 2. ed. Porto Alegre: Mediação, 2007. p. 166-175.

JESUS, D. M. O que nos impulsiona a pensar a pesquisa-ação colaborativo-crítica como possibilidade de instituição de práticas educacionais mais inclusivas? In: BAPTISTA, C. R.; CAIADO, K. R. M.; JESUS, D. M. (Org.). Educação especial: diálogo e pluralidade. Porto Alegre: Mediação, 2008. p.139-160.

JESUS, D. M. (Org.). Gestão da educação especial: pesquisa, política e formação. Curitiba: Appris, 2012. 
JESUS, D. M.; ALMEIDA, M. L. Pesquisa e educação especial: constituindo pistas de diálogo com a formação continuada. In: MARTINS, L. A. R.; PIRES, G. N. L.; PIRES, J. (Org.). Caminhos para uma educação inclusiva: políticas, práticas e apoios especializados. v. 1. João Pessoa: Ideia, 2014. p. 85-114.

MAINARDES, J. Abordagem do ciclo de políticas: uma contribuição para a análise de políticas educacionais. Educação \& Sociedade, Campinas, v. 27, n. 94, p. 47-69, abr. 2006.

ORGANIZAÇÃO DAS NAÇÕES UNIDAS PARA A EDUCAÇÃO, A CIÊNCIA E A CULTURA (Unesco). Declaração Mundial sobre a Educação para Todos: satisfação das necessidades básicas de aprendizagem: Jomtien, 1990. [s.l.]: Unesco, 1998a.

ORGANIZAÇÃO DAS NAÇÕES UNIDAS PARA A EDUCAÇÃO, A CIÊNCIA E A CULTURA (Unesco). Declaração de Salamanca sobre princípios, política e práticas na área das necessidades educativas especiais: 1994. [s.l.]: Unesco, 1998b.

PANTALEÃO, E. Formar formando-se nos processos de gestão e inclusão escolar. 2009. $218 \mathrm{f}$. Tese (Doutorado em Educação) - Programa de Pós-Graduação em Educação, Universidade Federal do Espírito Santo, Vitória, 2009.

PEREIRA, J. E. A pesquisa dos educadores como estratégia para construção de modelos críticos de formação docente. In: PEREIRA, J. E.; ZEICHNER, K. M. (Org.). A pesquisa na formação e no trabalho docente. v. 1. Belo Horizonte: Autêntica, 2002. p. 11-42.

PIOLLI, E.; SILVA, E. P.; HELOANI, J. R. M. Plano Nacional de Educação, autonomia controlada e adoecimento do professor. Cadernos CEDES, Campinas, v. 35, n. 97, p. 589-607, dez. 2015.

SABBATINI, R. M. E. Ambiente de ensino e aprendizagem via internet: a plataforma Moodle. São Paulo: Instituto EduMed, 2007. Disponível em: <http://www.ead.edumed.org.br/file.php/1/PlataformaMoodle.pdf>. Acesso em: 15 set. 2015

TONOLI, G. S. B. et al. Projeto político de políticas públicas da regional serrana (SRE Afonso Cláudio) de Formação Continuada em Educação Especial frente ao processo de inclusão escolar. Afonso Cláudio: Superintendência Regional de Ensino de Afonso Cláudio e Municípios da Região Serrana, 2014. 
VIEIRA, A. et. al. Formação de gestores de educação especial:

desafios e possibilidades. In: SIMPÓSIO BRASILEIRO DE POLÍTICA

E ADMINISTRAÇÃO DA EDUCAÇÃO, 25.; CONGRESSO IBERO-

AMERICANO DE POLÍTICA E ADMINISTRAÇÃO DA EDUCAÇÃO, 2.,

2011, São Paulo. Anais... São Paulo: Anpae, 2011. CD-ROM

ZEICHNER, K. M. Para além da divisão entre professor-pesquisador e pesquisador acadêmico. In: GERALDI, C. M. G.; FIORENTINI, D.;

PEREIRA, E. M. A. Cartografias do trabalho docente: professor (a)

pesquisador (a). Campinas: Mercado de Letras, 1998.

Recebido em 24 de julho de 2017.

Solicitação de correções em 6 de dezembro de 2017.

Aprovado em 14 de março de 2018. 